\title{
Ensenãnza superior y literatura infantil: una experiencia vivida en la carrera de pedagogía en Río de Janeiro
}

\begin{abstract}
Resumen: Este texto nació inspirado en la experiencia vivida por mí como formadora de profesores y, más específicamente, como docente de la disciplina "Alfabetización", ofrecida a estudiantes del tercero y cuarto período de la carrera de Pedagogía de la Facultad de Formación de Profesores de la Universidad del Estado del Río de Janeiro. Tomando la lectura como foco central en mis clases, busqué desarrollar un proyecto en las comisiones de la carrera de Pedagogía que fuese parte integrante de la disciplina "Alfabetización". ¿Cómo sería entonces, problematizar el propio proceso, alimentados por la idea freireana de que aprendemos a leer y a escribir durante toda la vida, lo que incluye el tiempo en que cursamos la graduación? Esta idea, anclada en otra igualmente potente, "sólo se aprende a leer, leyendo", produjo un proyecto de trabajo e investigación que comparto en este artículo.
\end{abstract}

Palabras-clave: Alfabetización. Formación docente. Lectura. Literatura infantil.

\section{Introducción}

Este texto nació inspirado en la experiencia vivida por mí como formadora de profesores $\mathrm{y}$, más específicamente, como docente de la disciplina "Alfabetización", ofrecida a estudiantes del tercero y cuarto períodos de la carrera de Pedagogía de la Facultad de Formación de Profesores de la Universidad del Estado do Río de Janeiro. La unidad de enseñanza a la cual me refiero y en la cual mi experiencia fue tejida está enraizada en una ciudad marcada por contradicciones: San Gonzalo. En ella, innumerables contrastes nos dan la dimensión de la complejidad que vive esta región, con reflejos en un importante microespacio: el aula.

Son Gonzalo, ciudad Metropolitana del Estado de Río de Janeiro, tiene contabilizada una población de más de 1.016.128 habitantes, según el Instituto Brasileño de Geografía y Estadística (IBGE) de 2012, alcanzando, así, la marca de segundo municipio más populoso del estado (detrás sólo de la capital). A pesar de este contingente poblacional, San Gonzalo es apuntado como el $46^{\circ}$ Producto Bruto Interno del país, teniendo en consideración investigaciones del IBGE. Estos dos números nos dan el calibre de las graves condiciones económicas y culturales en que vive esta población, apuntando, por otro lado, al poco caso en lo que se refiere a la producción e implementación de políticas públicas sociales.
Jacqueline de Fátima dos Santos Morais

Universidade do Estado do Rio de Janeiro - UERJ

jacquelinemorais@hotmail.com 
Otro dato que igualmente revela las desigualdades vividas en esta localidad es el Índice de Desarrollo Humano (IDH). San Gonzalo está en la $22^{\mathrm{a}}$ posición si tomamos como foco los municipios de Río de Janeiro. Es necesario recordar que el IDH es construido a partir de indicadores de calidad de vida, involucrando datos sobre educación (alfabetización y taza de matrícula), renta (PBI per cápita) y salud (esperanza de vida al nacer).

No podemos negar, sin embargo, que las investigaciones señalan una mejoría en los índices educativos nacionales como: reducción, aunque pequeña, del analfabetismo y aumento de la taza de matrícula de la población en edad escolar. Tales conquistas, empero, no han representado una mayor calidad en la escolarización de los que acceden a las instituciones de enseñanza. Un ejemplo de ello es la colocación del país en $88^{\circ}$ lugar en el ranking de educación de la Unesco.

Así, repitiéndolo una vez más, si por un lado tenemos hoy la casi totalidad de los niños matriculados en las escuelas brasileñas, lo que significaría una democratización del acceso a la escuela, por otro lado, esto no se ha traducido en una efectiva formación de alumnos lectores y escritores, usuarios competentes de la lengua, amantes de las palabras y sabedores de que escribir es registrar sus propias ideas y no meramente reproducir un texto producido por otro - en general un modelo textual empobrecido, presentes en libros de alfabetización y libros didácticos. No es difícil, por lo tanto, concluir que la enseñanza de la lectura y la escritura hegemónicamente encontrada en las escuelas, y de esta realidad no huye San Gonzalo, está marcada por la concepción bancaria del conocimiento denunciada por Freire (1997), y ha producido en las escuelas más copistas que autores de la propia palabra. La compra del libro de alfabetización Alfa y Beto por la Secretaria Municipal de Educación, por R\$ 526 mil, a fin de ser utilizada obligatoriamente por toda la red municipal de escuelas de San Gonzalo es un ejemplo de ello. Pautado en el método fónico, teniendo como punto de partida los fonemas de la lengua y su grafía, este material provocó numerosos debates y denuncias sobre el uso obligatorio del material por todos los docentes de los años iniciales, hiriendo la libertad y la autonomía docente en la elección de sus formas de enseñanza. Otro punto de controversia está en los textos presentes en el referido material didáctico. Frases de sentido dudoso como "Mi chaninha huele mal. Huele a olor a pies sucios" resultó en una 
denuncia realizada por el Sindicato Estatal de los Profesionales de Educación de Río de Janeiro (Sepe) al Ministerio Público del Estado. Si en otros estados la palabra "chaninha" significa chinela, en Rio de Janeiro esta palabra es entendida como una forma grosera de referencia al órgano sexual femenino. Así, no basta que la mayoría de los niños esté en la escuela sino que es necesario que ellos puedan encontrar sentido para su permanencia en el interior de este espacio. O, como afirma Freire, que los niños puedan encontrar en la escuela la vida real y, a partir de este encuentro, releer y ampliar su existencia en el mundo.

Pero también están los que ni siquiera pudieron experimentar el espacio escolar. Son hombres y mujeres a quienes no les fue asegurado el derecho social básico de aprender a leer y escribir. Datos apuntan que, en Brasil, 1legan a 14 millones. Y a pesar de una reducción media anual de 0,45 punto porcentual relativo a los últimos 16 años, manteniéndose esta velocidad, la escolarización de este contingente de los llamados analfabetos, que representa casi 10\% de la población brasileña, sólo deberá suceder dentro de 20 años - tiempo en el cual, es necesario decir, muchos de estos sujetos ya no estarán más vivos.

Otra investigación que buscó mapear los niveles de alfabetismo de la población brasileña fue realizada por el Instituto Paulo Montenegro. El resultado apunta que aproximadamente $75 \%$ de las personas entre 15 y 64 años no consiguen leer, escribir y calcular plenamente. De este porcentaje, más de 60\% son analfabetos funcionales y $7 \%$ son considerados analfabetos absolutos. Por otro lado, un levantamiento realizado en 2010 por el IBGE mostró que Brasil poseía, en este año, 30.558 millones de analfabetos funcionales. Lo más trágico es saber que, de estos sujetos, una buena parte frecuentó alguna institución escolar, pero no se tornó un usuario competente de la lengua escrita.

La consecuencia de esta realidad es el número expresivo de los que llegan a la universidad sin gran dominio de la lectura y la escritura.

Una investigación producida por el Instituto Paulo Montenegro (IPM) y por la ONG Acción Educativa reveló que, entre los estudiantes de la enseñanza superior, 38\% no dominan habilidades básicas de lectura y escrita. Aun sabiendo que es necesaria una mirada crítica sobre investigaciones de esta naturaleza, sin dudas, ellas traen elementos a ser discutidos. 
Pensar sobre estos índices, entre otros, se muestra fundamental si queremos comprender la extensión de los desafíos que involucran las dimensiones educativas, en especial aquellas vividas en la enseñanza superior. Si tomamos en cuenta una de las tareas de la universidad, que es la formación de sujetos que formarán otros sujetos, como es el caso do carrera de Pedagogía, más desafiadora se coloca esa actividad y más implicaciones y tensiones podremos percibir. La docencia en una universidad pública, especialmente cuando enraizada en un espacio contradictorio y complejo como es San Gonzalo, impone elecciones y decisiones no solamente epistemológicas, sino también, en especial, políticas. Esas decisiones, expresadas por acciones concretas en el mundo, revelan el deseo, como afirma Freire (2000, p. 33), de "que nuestra presencia en el mundo, implicando elección y decisión, no sea una presencia neutra". Y es justamente por la ausencia de neutralidad que todo acto de enseñar se presenta como un acto profundamente político, como, además, diría el propio Freire (1997, p. 24).

Y por ser político, los espacios educativos necesitan luchar para que la historia de desigualdad no se apague de la historia. Al final, como una vez más nos recuerda Freire (1997), es preciso: testificar, denunciar, no silenciar, no olvidar. O, también, Benjamin (1985, p. 223). para quien "nada de lo que sucede pode ser considerado perdido para la historia".

Es necesario no olvidar. Sentirse indignado. No dejarse 1levar por la inercia de la razón indolente de que fala Santos (2000). Y repetir, repetir - hasta que quede diferente. (BARROS, 1993)

Constataciones, como las anteriormente explicitadas, despertaron en mí la necesidad de avanzar de la indignación en dirección a acciones comprometidas con la transformación del cuadro expuesto. O, por lo menos, que representase una contribución, aunque pequeña, para que la ampliación de la lectura de la palabra resultase en la ampliación y problematización de la lectura del mundo, como defiende Freire (1989).

Así, tomando la lectura como foco central en mis clases, busqué desarrollar un proyecto en las comisiones de la carrera de Pedagogía que fuese parte integrante de la disciplina "Alfabetización". En estas clases privilegiamos las discusiones de naturaleza teórico-práctica a respecto de la enseñanza y el aprendizaje de la lectura y la escritura del otro. ¿Cómo sería, entonces, problematizar el propio proceso, alimentados por la idea freireana de que aprendemos a 
leer y a escribir durante toda la vida, lo que incluye el tiempo en que cursamos la graduación? Esta idea, anclada en otra igualmente potente, "sólo se aprende a leer, leyendo", produjo en mí la certeza de que era necesario leer para los alumnos y alumnas de la carrera de Pedagogía, ya que estos afirmaban que "leían muy poco", "sólo lo que era obligatorio para las materias" y que difícilmente sería encontrado un libro de literatura en sus mochilas y estantes.

Un pequeño cuestionario fue distribuido a los estudiantes y las respuestas pudieron ayudar a trazar el perfil de estos alumnos. Una de las preguntas se refería al conocimiento a respecto de los cuentos infantiles. De un universo de 57 alumnos matriculados en las dos comisiones de Alfabetización en las que daba clase en el año de 2012, sólo 11 decían conocer, a través de la lectura, los cuentos listados. Los demás alumnos, cuando afirmaban conocer Rapunzel, La Bella y la Bestia, o, inclusive, La Cenicienta, decían que había sido a través de obras cinematográficas como dibujos animados o películas. Los textos que habían originado tales versiones, no eran materia viva en sus vidas. O, por lo menos, no parecían ser. Estos estudiantes simplemente no habían leído estos cuentos. Ni siquiera habían escuchado que otros sujetos, como padres y profesores, hubiesen leído estas historias. “¿Pero Blancanieves no fue inventada por Walter Disney? ¿No? ¿Entonces, me engañaron toda la vida?” me dijo en cierta clase, una aluna del $4^{\circ}$ período de la carrera de Pedagogía.

No es difícil percibir por qué tantos alumnos conocen cuentos de hadas o fábulas sólo a través de las salas de cine, las pantallas de televisión o, más recientemente, por las pantallas de computadoras, tablets o notebooks. La cultura visual parece imponerse en los actuales tiempos, dejando espacio para el poder de penetración de los blockbusters. Hechos para ser vistos por el gran público, estas películas generan grandes lucros. Tales películas son basadas en cuentos e historias escritas hace mucho tiempo, a pesar de que algunas de ellas se alejan, y mucho, de la obra de referencia. Muchas de ellas tuvieron gran éxito económico. Alicia en el País de las Maravillas, de Tim Burton, por ejemplo, 1legó a rendir US\$ 1 billón en 2010. Blancanieves y el Cazador lanzado en los cines en 2012, alcanzó la lucrativa cifra de US\$ 396 millones. Estos son sólo dos ejemplos, pero podríamos listar aquí muchos otros.

Por otro lado, hemos visto una cierta tendencia, a que guionistas $\mathrm{y}$ directores realicen significativas modificaciones en las historias escritas como consecuencia de la transposición de las obras litera- 
rias para el cine. No raras veces bajo el pretexto de actualizar las historias infantiles.

Estas infidelidades, anunciadas como actualizaciones de las historias infantiles, acaban por crear nuevas obras, algunas de ellas muy distantes de las redactadas por sus autores.

No estoy aquí defendiendo a necesidad de "conservar la pureza de una obra literaria", maculada por los estudios. La transposición entre obra literaria y obra fílmica implica comprender que, muchas veces, las fronteras entre la obra original y el resultado en la pantalla de cine quedan borradas. La película, muchas veces, no cuenta la misma historia del libro porque hay diferencias entre lo que es representado literariamente en el libro y lo que es representado cinematográficamente en la película. Son diferentes sistemas de representación, lo que implica la producción de dos obras distintas. E1 problema, a mi entender, no está en la diferencia entre estos dos, sino en la capacidad, o imposibilidad, de que el espectador establezca relaciones entre estos dos lenguajes. Sin conocer la obra literaria, la versión fílmica se torna la única referencia, limitando sentidos y analogías.

En "Hansel y Gretel: Cazadores de Brujas", por ejemplo, Tommy Wirkola transforma en terror la historia criada en el siglo 19. Diferente de la versión original, en este película Hansel y Gretel son adultos traumatizados que cazan brujas con arcos y métodos sangrientos. Sin conocimientos previos relativos a la obra de los hermanos Grimm, parte de lo que podría ser visto como aspectos singulares de cada obra se pierde. ¿Cómo una obra representa a otra? ¿Qué elementos son privilegiados en una y no en la otra? Estas cuestiones sólo pueden ser respondidas se hubiese el conocimiento de las dos obras: la fílmica, pero también la escrita. Y es en esta segunda laguna que he puesto mis acciones sabiendo que la lectura de la palabra escrita implica la re-lectura del mundo, como afirma Freire (1997). Así, en todo inicio de clase de la carrera de Pedagogía, en la disciplina Alfabetización, leemos una historia infantil y hacemos de ella nuestra invitación para comprender el mundo pasado y presente.

\section{Literatura infantil en la carrera de pedagogía}

Con todos sentados formando casi una ronda, inicio la lectura

de una conocida historia, nacida en la tradición oral de la vieja 
Europa, transformada en texto escrito por Charles Perrault en la Paris del siglo XVII. La historia de una niña de caperucita roja, caminando sola por el bosque, yendo en dirección a la casa de su abuelita y viviendo el enfrentamiento con un temible lobo, siempre me pareció a mí naturalmente conocida. Estaba equivocada. Las narrativas escritas no son las formas privilegiadas de contacto con las historias.

Con miradas atentas, cerca de 30 alumnas de la carrera de Pedagogía esperaban, en silencio casi absoluto, el desenlace de la historia. Por fin, en la versión leída, un eximio cazador aparece en escena, disponiéndose a salvar a los personajes del peligro inminente. La confirmación del triunfo del bien trae otra certeza: la de que es preciso leer historias en el cotidiano escolar, aunque los alumnos sean adultos, aunque el espacio escolar sea el de una universidad.

Al cabo de la trama escuchada, algunas alumnas me dicen: "me encantó la historia", "como es bueno escuchar una buena historia", "¿me presta el libro? Quiero leérselo a mi hija".

Escenas como esta me hacen recordar que, frente a una buena historia, el oyente tiende a sentirse contagiado y a desear que no cese de repente la experiencia estética que vive. Frente a una buena historia y un buen narrador o narradora, deseamos la continuidad de la experiencia saboreada y nos atrevemos a querer revivirla, solos o, como en el casa de una de las alumnas, acompañada por la hija.

Fue Benjamin quien aprendió a "escuchar a contrapelo" las narrativas pertenecientes a la tradición oral, percibiendo en ellas un papel restaurador de la humanidad perdida en la modernidad y desarrollando sobre ellas una escucha sensible, Benjamin (1985, p. 205) nos recuerda que "contar historias siempre fue el arte de contarlas de nuevo, y ella se pierde cuando las historias no son más conservadas".

Sin duda, el arte de narrar siempre estuvo sumergido en las artes de la memoria y de la repetición. Es la repetición que, desde tiempos bien remotos, ha garantizado la preservación de lo vivido y de lo contado, de las experiencias colectivas e individuales, de la cultura de los pueblos. Desde siempre contamos y repetimos historias, permitiendo que en ellas sobrevivan las experiencias y tradiciones del lugar. Algunas, sin embargo, a lo largo del tiempo, tomaron la forma escrita, pues esta se tornó, en la modernidad, 
el lugar de preservación contra el tiempo y el olvido, no más el recuerdo.

Pero, como quien cuenta un cuento aumenta un punto... contar, o mejor, recontar, representa transmitir una vieja historia como se fuese nueva, pues al (re)contar una narrativa, esta acaba por ser modificada por el estilo de quien cuenta, acaba por ser cambiada por la selección de quien narra, por las interpretaciones de quien dice lo que escuchó. Contar es, pues, pasar adelante una historia que, siendo vieja, se torna nueva a cada día por la acción no sólo de la mirada de quien cuenta, sino también de quien escucha.

Las historias, nos dice Benjamin (1985, p. 205), se mantienen vivas más fácilmente en la memoria del oyente cuando son incorporadas a la propia experiencia, y en consecuencia "más irresistiblemente él cederá a la inclinación de recontarlas un día".

Aquellas alumnas de la carrera de Pedagogía no parecían inmunes al flujo de la narrativa de los cuentos infantiles leídos en sala. Tal vez porque aquellas historias evocasen y se inscribiesen en las experiencias de todas.

Leer historias es permitirse un encuentro con la narrativa, $\mathrm{y}$ esta...

[...] no está interesada en transmitir el puro en-si de la cosa narrada como una información o un informe. Ella sumerge la cosa en la vida del narrador para en seguida retirarla de él. Así se imprime en la narrativa la marca del narrador, como la mano del alfarero en la arcilla del florero (BENJAMIN,1985, p. 205).

Escuchar y leer historias infantiles es de cierta forma imprimir marcas en el texto y en los propios oyentes: marcas de la cultura de su grupo, marcas de otros grupos distantes, marcas que ni sabemos más cuáles son... Y esta relación entre quien narra y quien escucha recibe marcas también. Es así, leyendo y escuchando historias infantiles que un grupo de estudiantes de la carrera de Pedagogía iba enamorándose por el mundo de la narrativa escrita de los cuentos tradicionales.

Otro punto importante en las discusiones que provocaba con las alumnas era problematizar la idea de que la escuela debe "desarrollar el hábito de la lectura". Al final, la lectura, ¿debe ser vista como hábito? Esta pregunta remete a Bakhtin (1995, p. 92) y su defensa de que la palabra está siempre cargada de un contenido 
o de un sentido ideológico o vivencial. Los signos no son neutros, aunque aquellos que los produzcan puedan desear que así sea.

En la realidad, no son palabras lo que pronunciamos o escuchamos, sino verdades o mentiras, cosas buenas o malas, importantes o triviales, agradables o desagradables etc. La palabra está siempre cargada de un contenido o de un sentido ideológico o vivencial. (BAKHTIN, 1995, p. 95)

Como nos advierte Bakhtin (1995, p. 41), las palabras son tejidas a partir de una multitud de hilos ideológicos y sirven de trama a todas las relaciones, en todos los dominios. Las palabras son, por lo tanto, preñadas de "puntos de vista". Defender la lectura como hábito y no como atravesamiento de la vida, en la vida, es estar de cierto lado, defendiendo ciertas concepciones de lengua, de sujeto, de lectura.

Lectura no es hábito. Hábito implica repetición a fin de mecanizar la acción. No leemos sólo porque lo hicimos el día anterior. Leemos si y cuando esta acción se configura como acto de sentido. Por eso, implica conquista renovada, seducción constante. Leer representa un proceso de producción de sentidos que involucra leer la palabra y el mundo.

Maturana (2001) nos dice que sólo vemos lo que comprendemos. Si es verdad lo que este autor dice, para ver la vida transbordar de la lectura sería preciso comprenderla, entender su insistencia en resistir, su fragilidad en marginar nuestras acciones educativas, su fuerza utópica surgida cuando nada más parece posible. Leer es permitir vivir múltiples sentidos, múltiples posibilidades, múltiples destinos. Pero, ¿cómo traer la vida de los textos para el interior de nuestra actuación educativa? ¿Cómo profesoras que no leen pueden formar lectores? ¿Cómo dejar que las historias hablen en la clase si ellas se callan en la vida de las profesoras? ¿Cómo enseñar algo que no se vive?

El lugar de la literatura en la clase necesita ser asumido también en el espacio de formación de profesores. Sólo denunciar que los estudiantes de la enseñanza superior no leen, no produce cambios en esta realidad. Traer la literatura, de todo tipo, y en mi caso la literatura infantil, para la clase de la carrera de Pedagogía es ensanchar los espacios de la sala, ya que 
los actores de la práctica educativa (profesores y alumnos) están inmersos en la cultura, son autores, productores, creadores de lenguaje. Actores vivos de un conocimiento vivo y no siempre científico o sacralizado como tal... (KRAMER, 1993, p. 26)

Los estudiantes tienen derecho a tener acceso a la literatura producida por diferentes autores, de otros tiempos y lugares, y de tiempos y lugares próximos. Incorporar esa variedad de producciones humanas no significa tornarlas instrumento, mera mercadería de consumo, vaciada de sentidos. Al contrario, es tornarla viva en el cotidiano de la universidad y de la escuela, restaurar su aura de verdad, reconstruir historias que de ellas parecen surgir, luchar para que las experiencias vividas no desaparezcan. Para eso la pregunta de Benjamin (1985, p. 49) es siempre actual: “¿cuál es el valor de todo nuestro patrimonio cultural si la experiencia no se vincula más a nosotros?"

Abrir las puertas de la clase de la enseñanza superior para la literatura infantil permite incorporar producciones culturales que están a veces en silencio, invisibilidades en la vida de alumnos y alumnas. Pero para eso una vez más la palabra de Maturana (2001) se hace presente: sin comprender la literatura como expresión de la cultura producida por la humanidad, nuestros alumnos no verán la riqueza para sus vidas y de sus futuros alumnos.

Traer la literatura para la universidad, dejarse tocar por ella, sentirla involucrando los ojos, el cuerpo, sensibilizarse en este encuentro estético, resignificando lo visto/oído/sentido es fundamental en el espacio de formación docente, como lo es la carrera de Pedagogía.

Bartolomeu Campos Queirós (1999, p. 23) dice que el aprendizaje de la lectura sobrepasa el simple acto de presentar las letras al estudiante inicial. Formar lectores implica tomar la palabra e inscribirse en las palabras del otro:

Desconozco libertad mayor y más duradera que esta del lector cederse a la escritura del otro, inscribiéndose entre sus palabras y el silencio. Texto y lector sobrepasan la soledad individual para enlazarse por las interacciones. Este abrazo a partir del texto es la suma de las diferencias, movida por la emoción, estableciendo un encuentro fraterno y posible entre lector y escritor. Cabe al escritor estirar su fantasía para que, así, el lector pueda proyectar sus sueños. 


\section{La escritura docente como proceso de (auto)formación}

Benjamin (1985, p. 197) nos ayuda a comprender la importancia de la narrativa en la protección y conservación de las experiencias vividas, individuales y colectivas, en especial en un tiempo donde, como alerta el autor "el arte de narrar está en vías de extinción". Así, la experiencia que vivimos en la lectura de los cuentos infantiles en las clases de la disciplina Alfabetización en la carrera de Pedagogía representa tanto una lucha contra el olvido cuanto una defensa por el derecho a la palabra y al decir, aspectos que merecen atención en estos tiempos modernos. Por lo tanto, es necesario leer y releer las narrativas que formaron nuestra cultura.

Las historias comparten no sólo informaciones, sino también experiencias.

Leer y escuchar historias del repertorio infantil pueden movilizar las historias acomodadas en los sótanos de la memoria, poniendo en movimiento, a través de la palabra escrita, aquello que se vivió un día: la experiencia. Para tal, es importante recordar a Larrosa (2001, p. 25-26) al afirmar que "es experiencia aquello que nos pasa, lo que nos toca, lo que nos sucede, y al pasarnos nos forma y nos transforma". De esta forma, en las clases de Alfabetización de la carrera de Pedagogía he estimulado a las estudiantes a rememorar narrativas escuchadas en la infancia, a traer libros que fueron parte de sus vidas cuando eran pequeñas a fin de compartir historias significativas. De esta forma, busqué que la actividad de lectura en la y para la comisión se configurase en una experiencia.

\section{Algunas reflexiones finales}

A fin de comprender las actividades de lectura en la escuela más allá de un sentido meramente práctico, sino también de vislumbrar las teorías del conocimiento que las (in)forman (y así poder decidir se concordamos o no con ambas - actividades y concepciones teóricas), necesitamos problematizar la idea de que una cosa es la práctica y otra bien diferente es la teoría. Ambas, teoría y práctica, se implican y se constituyen en el cotidiano escolar, no estando nunca una apartada de la otra. Aunque no tengamos consciencia de esta relación. Aunque no sepamos que las actividades curriculares presentes en los innumerables manuales didácticos dirigidos tanto a futuros docentes cuanto a profesores en actuación, más que 
inocentes instrucciones didácticas de carácter práctico, cargan, en su interior, una teoría implícita. Digo esto para afirmar que leer historias del repertorio denominado infantil para adultos que están en proceso formativo revela y se alimenta de concepciones teóricas: de cómo pensamos que estudiantes aprenden a ser docentes, de cómo creemos que debamos enseñarles a ser profesores, de lo que defendemos ser conocimiento validado en la universidad, de lo que entendemos por universidad, de lo que para nosotros significa currículo de una disciplina en la universidad - para decir sólo parte de las implicaciones/imbricaciones de esta actividad.

Es cierto que al optar por la lectura de textos clásicos llamados académicos o por historias publicadas para un público infantil, lo hacemos porque poseemos un conjunto de creencias sobre lo que sea un texto que contribuya mejor para el proceso de enseñar y aprender. Esas creencias y valores nos habitan y es con ellas que operamos en clase, sabedoras de ello o no. Tal vez por esta razón Freire (1997, p. 24), ha defendido intensamente la importancia de la reflexión crítica sobre la práctica, pues "esta se torna una exigencia de la relación teoría/práctica sin la cual la teoría puede ir tornándose blablablá y la práctica, activismo."

Reflexionar sobre lo que hacemos en nuestras clases, con nuestros alumnos y alumnas es una necesidad de quien está comprometido en tejer una escuela más favorable a todos: alumnos y profesoras, sea en la escuela básica, sea en la universidad. Vale recordar que ningún aprendizaje escolar se hace en la neutralidad de la acción docente. Todo acto educativo, y en él destacamos la enseñanza y el aprendizaje de leer y escribir, está concomitantemente incluido también en una dimensión educativo-política. Hace más de cuatro décadas Freire ya alertaba para esta dimensión, afirmando que el hombre necesita desarrollar su capacidad de "leer el mundo" para en el intervenir, no como sujeto que bajo el discurso de la autonomía se torna individualista, sino como sujeto perteneciente a un colectivo que desarrolla formas de acción solidaria. Es necesario leer el mundo para transformarlo no para si, sino para todos. Participar y contribuir con la emancipación no como individuo aislado, sino como un sujeto perteneciente a un colectivo de otros sujetos. Y pienso que las lecturas realizadas en clase que extrapolen las "tradicionales" pueden contribuir para este proceso de pertenecimiento y emancipación. 
Pensamos, fortalecidas por las palabras de Freire, que también nosotras, profesoras, necesitamos "leer el mundo" y crear estrategias colectivas de emancipación, realizando lo que Santos (2006, p. 41) delinea como la agregación de voluntades y la creación de subjetividades que protagonizan acciones transformadoras colectivas. En este sentido de colectividad está incluido el trabajo con la lectura de cuentos infantiles en la carrera de Pedagogía de la Facultad de Formación de Profesores de la UERJ.

La literatura infantil es muchas veces una extraña en el espacio universitario. Tantas veces invisibilizada, representada como objeto menor, destinada a los que saben poco, vivieron poco, comprenden poco: los niños. Es necesario, sin embargo, entender la relevancia de esta producción humana para la constitución del conocimiento. Lo que vemos en pauta es la necesidad de rediscutir saberes y haceres universitarios, en especial los que se refieren a la formación docente.

Concordando con Santos (2006, p. 82) pienso que es necesario "recuperar la capacidad de espanto y de construir de modo a poder traducirse en inconformismo y rebeldía". Datos como los presentados a lo largo del texto sobre la dimensión de la lectura en la vida de los brasileños necesitan movilizar nuestro inconformismo, despertar nuestra rebeldía, incomodarnos a punto de provocar acciones. Nuevas acciones, pues "de lo que necesitamos con más urgencia es de una nueva capacidad de espanto y de indignación, que sustente una nueva teoría y una nueva práctica inconformista, desestabilizadora, en suma, rebelde." (SANTOS, 2006, p. 82)

Es la rebeldía de la no conformidad con lo que parece haber sido siempre así que puede engendrar nuevas posibilidades de mirar y vivir la lectura en la universidad. La literatura infantil nos invita a construir nuevos sentidos para la acción educativa. Potencializa el rompimiento con las viejas formas instituidas de hacer y pensar el mundo. Instiga a crear nuevas maneras de aprender a leer la palabra y el mundo. Al final, estamos todos en proceso de aprendizaje: aprender a releer de forma más crítica el mundo como camino para reescribirlo, para transformarlo. 


\title{
Ensino superior e literatura infantil: uma experiência vivida em um curso de pedagogia no Rio de Janeiro
}

resumo: Este texto nasceu inspirado na experiência vivida por mim como formadora de professores e, mais especificamente, como docente da disciplina "Alfabetização", oferecida a estudantes do terceiro e quarto período do curso de pedagogia da Faculdade de Formação de Professores da Universidade do Estado do Rio de Janeiro. Tomando a leitura como foco central em minhas aulas, busquei desenvolver um projeto nas turmas do curso de pedagogia que fosse parte integrante da disciplina "alfabetização". Como seria então, problematizar o próprio processo, alimentados pela ideia freireana de que aprendemos a ler e escrever durante toda a vida, o que inclui o tempo em que cursamos a graduação? Este mote, ancorado em outra ideia igualmente potente, "só se aprende a ler, lendo" produziu um projeto de trabalho e pesquisa que neste artigo compartilho.

Palavras-chave: Alfabetização. Formação docente. Leitura. Literatura infantil.

\section{Superior teaching and children's literature: an experience lived in the pedagogy couser in Rio de Janeiro (Brazil)}

\begin{abstract}
This text was born inspired by the experience of me as a teacher trainer and, more specifically, as a teacher of the discipline "Literacy", offered to students of the third and fourth period of the pedagogy course of the Faculty of Teacher Training of the State University of Rio of January. Taking reading as a central focus in my classes, I tried to develop a project in the classes of the pedagogy course that was an integral part of the "literacy" discipline. What, then, would it be like to problematize the process itself, nourished by the Freirean idea that we have learned to read and write throughout our lives, which includes the time in which we are studying? This motto, anchored in another equally powerful idea, "one only learns to read, reading" produced a project of work and research that I share in this article.
\end{abstract}

Keywords: Literacy. Teacher Training. Reading. Children's Literature.

\section{Referencias}

BARROS, Manoel de. O libro de las ignorãças. Río de Janeiro: Record,1993.

BAKHTIN, Mickhail (Volochinov). Marxismo y Filosofia de la Linguagem. São Paulo: Hucitec, 1995.

BENJAMIN, Walter. Obras Escolhidas. São Paulo: Brasiliense, 1985.

BENJAMIN, Walter. Origem do drama barroco Alemão. São Paulo: Brasiliense, 1984.

FREIRE, Paulo. Pedagogía de la esperança: un reencontro con a Pedagogía do oprimido. São Paulo: Editora Unesp, 1997.

FREIRE, Paulo. Pedagogía de la indignação: cartas pedagógicas y otros escritos. São Paulo: Editora Unesp, 2000. 
FREIRE, Paulo. A importância do ato de leer: en três artigos que se completam. São Paulo: Editora Cortez, 1989.

FREIRE, Paulo. Alfabetización: concepções y imagens de enseñanza, aprendizagem y língua no cotidiano escolar. In: PLETSCH, Márcia Denise; RIZO, Gabriela (org.). Cultura y formación: contribuições para a práctica docente. Seropédica: Editora da UFRRJ, 2010.

KRAMER, Sonia. Por entre as pedras: arma y sonho en la escuela. São Paulo: Ática, 1993.

LARROSA Jorge. Nota sobre a experiencia y o saber de la experiencia. Leituras SME, Campinas, julho 2001.

MATURANA, Humberto. A ontologia de la realidad. Belo Horizonte: Editora da UFMG, 2001.

PERRAULT, C. Cuentos de Perrault. Belo Horizonte: Itatiaia, 1989.

QUEIRÓS, Bartolomeu Campos. O libro es passaporte, es bilhete de partida. In: PRADO,Jason. ; CONDINI, Paulo. (org.). A formación do leitor: pontos de vista. Rio de Janeiro: Argus, 1999, p. 23-24.

SANTOS, Boaventura de Souza. A crítica de la razão indolente. São Paulo: Cortez, 2000.

SANTOS, Boaventura de Souza. A gramática do tiempo. São Paulo: Cortez, 2006. 